\title{
GESTÃO DE RESÍDUOS E \\ UTILIZAÇÃO DE JOGO \\ ELETRÔNICO PARA A \\ EDUCAÇÃO AMBIENTAL
}

Cibele Bender Raio ${ }^{1}$

Resumo: A gestão dos resíduos da ETEC Augusto Tortolero Araújo foi realizada pelos alunos do $1^{\circ}$ ano do Ensino Médio. Um questionário diagnosticou o conhecimento e as ações dos alunos quanto à separação dos resíduos. As lixeiras da escola foram identificadas como "reciclável", "orgânico" e "rejeito" e outras foram instaladas em locais estratégicos. O material reciclável coletado foi destinado à cooperativa local. Também, foi disponibilizada uma urna para coleta de resíduo perigoso. Por fim, os alunos desenvolveram um jogo virtual, uma ferramenta de conscientização ambiental propagado à comunidade escolar de todo o município. A gestão foi apoiada pelos alunos e servidores e a prática "Utilização de Games para práticas de educação ambiental" foi uma das vencedoras do prêmio "Respostas para o Amanhã", da Samsung.

Palavras-chave: Autonomia; Coleta Seletiva; Metodologia Inovadora; Reciclagem. 


\section{Introdução}

As ciências (biológica, física, química e matemática) passaram por grandes modificações quanto aos seus objetivos em relação à variação da política e economia, no nosso país e no resto do mundo. Historicamente, após segunda guerra mundial, buscou-se a formação de alunos para uma autonomia científica, retratada na LDB 1961.

Com a entrada do governo militar no Brasil, a educação passou a ter objetivo de moldar o trabalhador, como é possível observar na LDB de 1971. E mais recentemente, em um contexto de Globalização, a LDB de 1996, estabelece a educação voltada para o mercado de trabalho e a formação social. Espera-se que a escola forme o cidadão-trabalhador-estudante, incluindo a formação ética e a autonomia intelectual (KRASILCHIK, 2000).

Para a formação de um indivíduo crítico, autônomo e ciente do papel da escola em sua formação é necessário o diálogo como pressuposto para a busca da igualdade, onde todos têm direito a voz e se educam mutuamente (FREIRE, 1996). A autonomia do estudante é, também, um dos principais pontos defendidos por outros grandes educadores que trabalham com metodologias inovadoras de ensino, como: José Pacheco, Sebastião Rocha, Rubem Alves e Ken Robinson.

Entre as formas inovadoras de ensino, muitas sugerem o trabalho pedagógico em forma de projetos (ver exemplos em PACHECO et al, 2006 e GRAVATÁ et al., 2013). O Centro Paula Souza que, desde 2001, incorporou à grade curricular disciplinas-projeto, contemplando diversas áreas do conhecimento, incentiva e apoia práticas pedagógicas com metodologias alternativas de ensino.

Em 2013, a ETEC Augusto Tortolero Araújo inseriu no primeiro ano do Ensino Médio a disciplina de "Ações em Defesa e Proteção ao Meio Ambiente". No ano de 2014, o tema escolhido para ser trabalhado foi a "Gestão dos Resíduos Sólidos da escola". A escolha do tema se justificava pelo fato de que a escola não participava da coleta seletiva mesmo que, desde 2010, com a Lei 12.305, Política Nacional de Resíduos Sólidos, a responsabilidade pelos resíduos gerados é compartilhada, com obrigações que envolvem os cidadãos, as empresas, as prefeituras e os governos.

Diante deste cenário, programas de Educação Ambiental são extremamente necessários para a propagação da importância da separação dos resíduos. Pois, como verificado em outros municípios, o sucesso e efetivação do processo de reciclagem dependem da educação (PERSICH; SILVEIRA, 2011).

Em Paraguaçu Paulista, a coleta do resíduo reciclável é realizada pela COOPACAM - Cooperativa Paraguaçuense de Coleta de Materiais Recicláveis, criada em 2011 com auxílio da incubadora de Cooperativas Sociais da UNESP - Assis. Um dos maiores problemas relatados pelos cooperados é a não separação dos resíduos pela população. Esta situação é agravada pelo fato de 
o aterro sanitário da cidade de Paraguaçu Paulista estar com a sua licença suspensa, por ter atingindo a sua capacidade suporte.

Durante o desenvolvimento das atividades do projeto, um dos alunos demonstrou desinteresse em participar das atividades. Assim, a professora o questionou sobre o que gostava de fazer, pois não participava nem das atividades mais diferenciadas, o aluno respondeu que só gostava de jogar em computadores. Neste momento, a professora solicitou que ele se reunisse com seus colegas e desenvolvesse um jogo com o tema "Meio Ambiente". Duas semanas depois, os alunos apresentaram uma versão demonstrativa de um jogo que estimula a separação do material reciclável.

A prática se enquadrou perfeitamente ao edital do prêmio "Respostas para o Amanhã", da Samsung, que tinha como objetivo identificar, estimular e difundir práticas educativas do Ensino Médio da rede pública de ensino que apresentassem soluções simples para transformar a realidade local, e se consagrou como uma das vencedoras nacionais do concurso.

O projeto realizado resultou no diagnóstico dos problemas de resíduos sólidos da ETEC Augusto Tortolero Araújo, implantou a reciclagem com destinação dos resíduos para a cooperativa de catadores de reciclável da cidade e propagou a conscientização ambiental quanto à importância da separação dos resíduos e a destinação correta para a cooperativa em toda a comunidade escolar da rede pública de Paraguaçu Paulista, utilizando como ferramenta o jogo virtual interativo.

Além de beneficiar a cooperativa de catadores, que atualmente possui 34 cooperados, e gerar uma ferramenta para trabalhar o tema em outras escolas. O presente projeto atingiu o objetivo do Ensino Médio, proposto pela LDB atual, ao ser aproveitado o momento cognitivo particular dos jovens para promover a autonomia para aprender, concretizando habilidades e competências em ações, objetos e experiências. A premiação pela Samsung foi o reconhecimento de todos esses benefícios.

\section{Material e métodos}

O projeto "Gestão de Resíduos" foi realizado durante as atividades da disciplina de "Ações em Defesa e Proteção ao Meio Ambiente", com os alunos do primeiro ano do Ensino Médio da ETEC Augusto Tortolero Araújo, durante janeiro a dezembro de 2014. As atividades do ano letivo foram planejadas previamente e constituem o Plano de Trabalho Docente - PDT da disciplina. Formulado com base na Lei $n^{\circ} 9.795$, de 27 de abril de 1999, que institui a Política Nacional de Educação Ambiental.

O presente trabalho foi uma pesquisa-ação (THIOLLENT, 1986, p.14), ou seja, foi concebida e realizada em associação estreita com a resolução de um problema coletivo, a separação do resíduo escolar, onde todos os envolvidos, alunos, professores e servidores, participaram de forma coletiva. 
O projeto foi dividido em três etapas: diagnóstico, ação e propagação. $O$ diagnóstico a respeito do conhecimento dos alunos sobre os resíduos recicláveis no município de Paraguaçu foi realizado através de um questionário, elaborado pelos próprios estudantes, com nove questões (ANEXO 1), aplicado à 103 estudantes.

$\mathrm{Na}$ segunda etapa, os alunos contabilizaram e identificaram todas as lixeiras da escola com: reciclável, orgânico e rejeitos. Todos os departamentos, salas de aula, alojamento e o pátio foram visitados por cinco grupos de alunos que contaram cada uma das lixeiras. Uma urna de coleta de pilhas, baterias e lixo eletrônico foi instalada na biblioteca e o material recolhido destinado, sempre que necessário, ao CIVAP - Consorcio Intermunicipal do Vale do Paranapanema.

Os adesivos das lixeiras e da urna seguiram o padrão de cor definido pela Resolução 275/01 do Conselho Nacional do Meio Ambiente: Orgânico marrom; Rejeito - cinza e Resíduo Perigoso - laranja. A resolução recomenda que os resíduos recicláveis sejam separados seguindo o código em várias cores. No presente plano de gestão de resíduos, as lixeiras foram todas identificadas com adesivos de uma mesma cor, o verde, escolhido por representar o Meio Ambiente. Aqui é defendido que não há a necessidade de separar cada tipo de resíduo reciclável, pois a própria cooperativa faz a triagem do material em seu barracão. Não se fazendo necessária a separação prévia.

Entre as atividades de conscientização, os alunos do primeiro ano participaram de uma capacitação sobre a importância da destinação de material reciclável para a cooperativa de catadores de material reciclável de Paraguaçu Paulista. O evento foi promovido pelo Desenvolvimento Regional Sustentável, do Banco do Brasil, Prefeitura Municipal, COOPACAM, UNESP e Caá Consultoria Ambiental.

$\mathrm{Na}$ escola, foram realizadas palestras com alunos e servidores com o objetivo de conscientizar a todos sobre os problemas ambientais que a destinação incorreta do resíduo pode acatar ao meio ambiente, e à economia da cidade, e sobre os benefícios sociais, ambientais e econômicos gerados com a destinação correta de cada tipo de material. As palestras buscavam ainda a adesão coletiva à gestão dos resíduos da escola, ou seja, com os alunos separando $o$ material em lixeiras corretas $e$ os servidores, especialmente os responsáveis pela limpeza, destinar corretamente o material.

$\mathrm{Na}$ terceira etapa, os alunos elaboraram um jogo virtual para propagar e divulgar a separação dos resíduos em outras escolas. Esta etapa não estava programada no plano de trabalho docente.

A programação do jogo surgiu por conta das circunstâncias apresentadas em sala. Um aluno, que não se enquadrava no modelo tradicional de ensino e que não participava das aulas foi questionado pela professora quanto ao que gostava de fazer, pois se rejeitava a participar de todas as atividades propostas. $O$ aluno respondeu que só gostava de jogar jogo de computador, assim a professora o estimulou realizar uma prática de seu

revista brasileira educação ambiental 
interesse. O aluno, junto com seus colegas, programou um jogo sobre educação ambiental, que roda em plataforma HTML5, em computadores e Android a partir de 4.0. Toda programação do jogo foi realizada a partir da busca dos alunos e consultas na internet e não contou com auxílio profissional.

No mesmo período, esta prática pedagógica foi submetida ao edital do prêmio "Respostas para o Amanhã", da Samsung, com coordenação técnica do Cenpec. E recebeu vários prêmios por ser uma das práticas vencedoras nacionais.

Ao ser selecionado como um dos vinte finalistas, o projeto tomou maiores proporções e envolveu todos os alunos da sala, que apresentaram as suas habilidades e trabalharam na divulgação do jogo para outras escolas de Paraguaçu Paulista. Os alunos que se identificavam com desenhos, produziram a figura do personagem principal do jogo e de protótipos de cartazes para a divulgação. Uma aluna que participa de um projeto musical municipal compôs e, junto com outro colega da sala, tocou a trilha sonora do jogo. Um grupo de alunos ficou responsável pelo contato com as escolas, outros pela logística de transporte. A aluna, que se demonstrou proativa, cuidou da gestão dos grupos. Enfim, todos os alunos participaram de alguma forma.

Por ser classificado entre os vinte finalistas do prêmio Samsung, a escola recebeu um notebook e uma câmera fotográfica e filmadora. Nesta etapa do projeto, foi gravado um vídeo para a escolha dos vencedores nacionais (disponíveis em PRÊMIO RESPOSTAS PARA O AMANHÃ, 2014).

A prática pedagógica foi eleita como uma das cinco vencedoras nacionais, nesta etapa cada um dos alunos da sala foi premiado com uma câmera fotográfica. A professora responsável pela prática e a diretora da escola ganharam um tablet, cada. A premiação ainda deu a possibilidade de cinco alunos, acompanhados da professora, participar do $1^{\circ}$ Encontro Latino Americano Sobre Educação, da Samsung. Onde os trabalhos foram apresentados e os prêmios a as medalhas foram entregues.

\section{Resultados verificados}

Entre os alunos entrevistados, 22,33\% afirmaram que separam os seus resíduos, 53,4\% responderam que separam em parte. A maioria, 93,2\% concorda que é importante a separação dos resíduos, sendo que 78,64\% incentivam, de alguma forma, outras pessoas a também separarem, ao menos em parte (46,6\%). 88,35\% dos entrevistados afirmam saber, ao menos em parte $(33,01 \%)$ para onde vai o lixo que produz. $83,5 \%$ afirmam reconhecer o tipo de resíduo quanto "rejeito", "orgânico" ou "reciclável". 19,42\% não tem conhecimento de onde deve descartar pilhas e baterias. 31,07\% não sabiam que existe uma cooperativa de catadores no município. 69,9\% afirmam que passa algum grupo de catadores no bairro em que vive, e $14,56 \%$ diz que é esporádica a presença de catadores em seu bairro. Por fim, 95,15\% dos alunos acreditam que a escola deveria separar os seus resíduos.

Revbea, São Paulo, V.11, № 2: 192-202, 2016. 
A partir desses dados é possível notar que os alunos têm conhecimentos sobre a importância da reciclagem, dominam os termos "rejeito", "reciclável" e "orgânico" e apoiam a separação na escola. Ainda que, muitos não praticam a separação de seus resíduos em suas residências.

É possível notar que a cooperativa é reconhecida pela maioria dos alunos, no entanto, ainda não apresenta total eficiência em todos os bairros da cidade. Uma vez que $39,1 \%$ dos estudantes afirmam que não há um grupo de catadores passando frequentemente em seu bairro.

Quanto ao resíduo perigoso, pilhas e baterias, é um dado preocupante a quantidade de alunos que não sabiam onde descartá-los. Agora contam uma urna para a coleta deste material. A disposição da urna na biblioteca foi escolhida por conta de experiências relatadas pelo responsável pelo projeto do CIVAP, que relata a presença de mistura de restos de alimento com o material coletado. A biblioteca é um local onde os alunos não entram com alimentos, assim, evita a mistura de resíduos na urna.

Durante os meses de maio e junho, os alunos contabilizaram 127 lixeiras distribuídas na escola e reivindicaram mais lixeiras para orgânicos em áreas de refeição. Além disso, identificaram todas conforme a classificação do lixo a ser depositado: rejeito, orgânico ou reciclável (Figura 1).

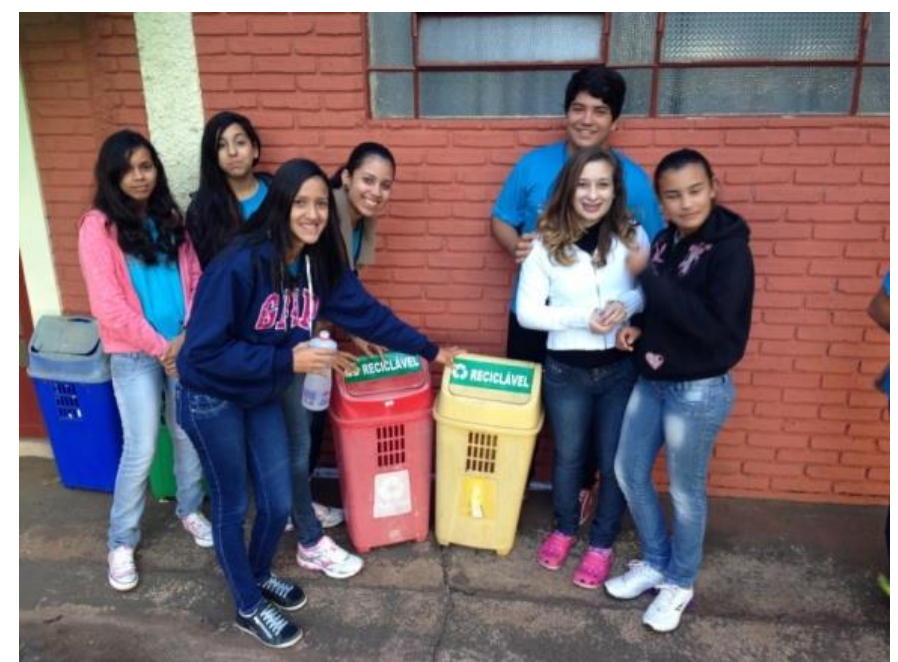

Figura 1: Alunos do $1^{\circ} \mathrm{A}$ instalando adesivos com uma única identificação para as lixeiras abrigarem todos os tipos de resíduos recicláveis.

Em 19 de março de 2014, os alunos participaram de uma capacitação sobre a importância da destinação de material reciclável para a cooperativa de catadores de material reciclável da cidade.

Em 29 de março de 2014, a professora da disciplina participou como voluntária, de um movimento de sensibilização sobre a importância da separação dos resíduos e doação deste material para a COOPACAM, ação resultante do evento anterior. No movimento, o maior bairro da cidade (Barra 
Funda) foi percorrido pelos voluntários que batiam de casa em casa conscientizando a população sobre a importância da separação dos resíduos e doação para a cooperativa local.

$\mathrm{Na}$ semana do meio ambiente, a professora coordenadora do projeto proferiu palestras expositivas para os alunos do Ensino Médio e Técnico, com a apresentação do projeto e reflexões sobre a conscientização ambiental.

Em 31 de julho de 2014 foi realizada uma palestra expositiva para os servidores da escola, com a apresentação do projeto, conscientização ambiental e elaboração de planilha com departamentos geradores de resíduos, tipos de resíduos, freqüência da coleta e destinação e elaboração de planos e metas. Neste mesmo dia, foi disponibilizado um bag da COOPACAM para coleta e armazenamentos dos resíduos recicláveis produzidos durante a semana.

Nos quatro primeiros meses após a implantação do projeto, a escola separou e destinou a cooperativa local, aproximadamente uma tonelada de resíduos, em média, $60 \mathrm{Kg}$ semanais. O material orgânico já era, e continuou sendo, doado para compostagem. E agora somente o rejeito é coletado pela coleta municipal.

No dia 06 de agosto de 2014 uma bomba de captação de pilhas, baterias e celulares antigos, foi instalada na biblioteca da escola. A bomba e adesivo de divulgação foram doados pelo CIVAP e a bomba foi personalizada, durante as aulas, com temas relacionados ao Meio Ambiente (Figura 2).

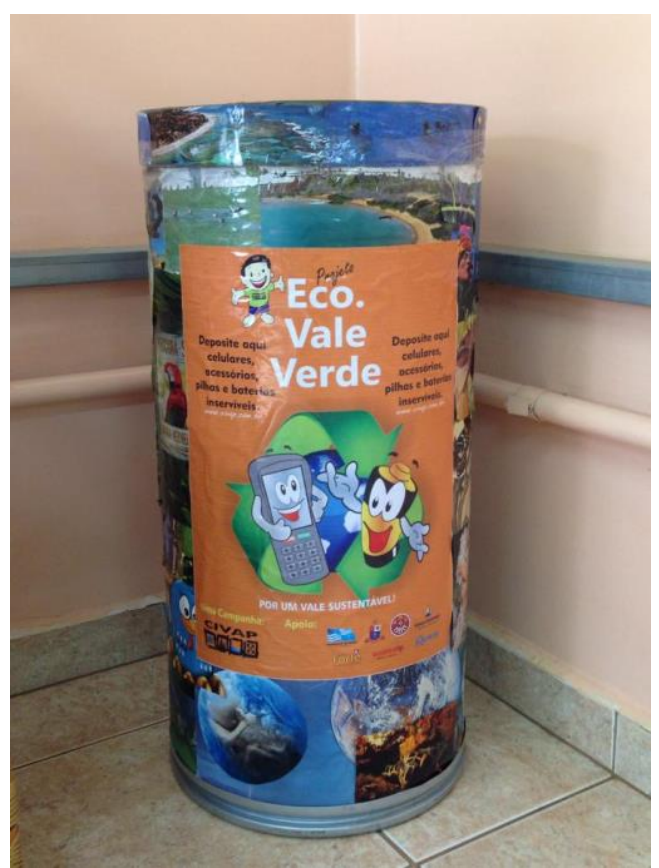

Figura 2: Bomba coletora de pilhas, baterias e aparelhos celulares antigos, instalada na biblioteca da escola. 
Em agosto, os alunos desenvolveram um projeto para a propagação da reciclagem através de um jogo para computador e smartphone, denominado por eles de Flying alone (Figura 3). E neste mesmo mês o projeto foi submetido ao Prêmio Respostas para o Amanhã da Samsung.

$\mathrm{O}$ jogo consiste em um desafio onde um personagem (urubu) passa através de latas de lixo. $O$ jogador que conseguir desviar de um maior número de latas é o vencedor. Quando o jogador perde é necessário que responda a uma questão relacionada ao meio ambiente para que o jogo volte a rodar. Essa ferramenta pode ser utilizada para chamar a atenção dos jovens para a discussão dos problemas dos resíduos na cidade, no início de uma aula ou atividade de educação ambiental.

Durante os meses de setembro e outubro o jogo foi aperfeiçoado e foi incluída a participação de todos os alunos. Cada responsabilidade foi definida através de da habilidade relatada pelos próprios alunos. Por exemplos, se envolveram compondo a trilha sonora, desenhando cartazes de divulgação e organizando a logística das visitas às escolas.

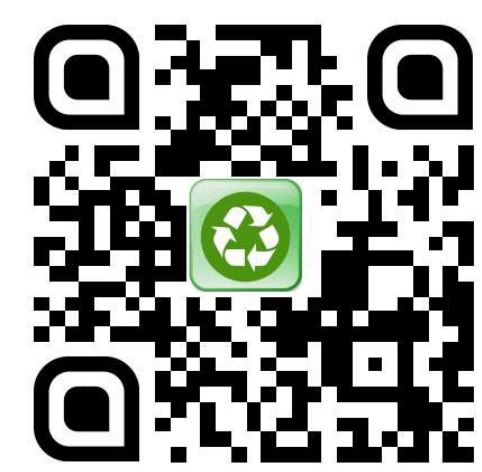

Figura 3: QRcode de acesso ao jogo programado pelos alunos do $1^{\circ}$ do Ensino Médio durante as atividades da disciplina de Ações em Defesa e Proteção ao Meio Ambiente. Também disponível no link q-r.to/098n.

No dia 26 de novembro duas escolas foram visitadas e os alunos apresentaram a importância social, econômica e ambiental da separação dos resíduos e destinação correta à cooperativa de recicláveis. A proposta é continuar visitando as escolas no próximo ano, para que todas as escolas públicas da cidade tenham acesso ao projeto. O jogo, também, foi disponibilizado em um jornal de circulação local, em redes sociais, ao CIVAP e ao Centro de Educação Ambiental do Município.

A inserção do jogo no projeto de Gestão de Resíduos foi uma das cinco práticas pedagógicas vencedoras do Prêmio Resposta para o Amanhã, da Samsung. Que premiou práticas simples de transformação da realidade local. Em dezembro, cinco alunos, acompanhados da professora responsável pelo projeto, foram a São Paulo receber as premiações e participar do $1^{\circ}$ Encontro Latino Americano de Educação da Samsung. 
Neste evento, ainda foi premiada a grande vencedora do concurso, a escola Tristão de Barros, da cidade de Currais Novos - RN com a prática "Equilíbrio - para uma inclusão sustentável e um meio ambiente melhor" e conhecida a prática favorita do júri popular "Ecofiltro: Carvão Ativado do pecíolo da folha da carnaúba (Copernicia prunifera) para o tratamento d'água", da Escola Murilo Braga, de Martinópole (CE).

Após as atividades de implantação do Programa de Gestão de Resíduos Sólidos na escola, foi verificada uma mudança de atitude por parte dos alunos e dos servidores. Funcionárias da limpeza mostraram-se conscientes da necessidade de separação dos resíduos, por iniciativa própria instalaram mais uma lixeira na copa e cartazes com instruções para que o resíduo reciclável e orgânico fosse separado corretamente.

A Educação Ambiental, pela Lei 12.608, deve ser incluída aos currículos de ensino fundamental e médio de forma integrada aos conteúdos obrigatórios. que exige dedicação e melhoria contínua. No entanto, muitos professores apresentam dificuldades de sair do cotidiano, do método de educação tradicional, e implantar um projeto ambiental com trabalho prático, como relatado por Souza et al. (2013). O desenvolvimento do trabalho foi facilitado por ser inserido em uma disciplina projeto. Vale destacar o relato de um aluno da disciplina que disse que estuda reciclagem desde as séries iniciais, no entanto, só eram resolvidos alguns exercícios na apostila e nunca antes havia visto reciclagem na prática.

\section{Considerações finais}

A partir do diagnóstico foi possível observar que os alunos apresentaram conhecimento e certa preocupação com o processo de reciclagem, sendo que a separação dos resíduos na escola foi apoiada pela grande maioria. Após da inserção da separação, os alunos seguiram as indicações e elogiaram a identificação de todas as lixeiras com adesivos "reciclável", "orgânico" e "rejeito", além disso, reivindicaram lixeiras específicas em locais onde havia só um tipo de lixeira. Ainda, os alunos trouxeram de suas casas pilhas, baterias e aparelhos celulares antigos para serem depositados na urna de coleta de resíduos perigosos. As palestras e capacitações foram essenciais para o sucesso da gestão de resíduos. O desenvolvimento do projeto possibilitou um campo para ser inserida a realidade dos alunos, que programaram um jogo sobre o tema e utilizaram como ferramenta para propagação da conscientização ambiental para outras escolas do município, a prática pedagógica foi uma das vencedoras do Prêmio Respostas para o Amanhã, da Samsung. 


\section{Referências}

BRASIL. Lei $\mathbf{n}$. 12.608, de 10 de abril de 2012. Inclui a educação ambiental de forma integrada ao Ensino Fundamental e Médio. Disponível em <http://www.planalto.gov.br/ccivil 03/ Ato2011-2014/2012/Lei/L12608.htm>.

Acesso em 04 de dez. de 2014.

BRASIL. Lei n. 12.305, de 2 de agosto de 2010. Institui a Política Nacional de Resíduos Sólidos. Disponível em <http://www.planalto.gov.br/ccivil 03/ ato2007-2010/2010/lei//12305.htm>. Acesso em: 12 set. 2014.

BRASIL. Lei n. 4.024, de 20 de dezembro de 1961. Estabelece as diretrizes e bases da educação nacional. Disponível em <http://www.planalto.gov.br/ccivil 03/leis//4024.htm>. Acesso em 18 set. 2014.

BRASIL. Lei n. 5.692, de 11 de agosto de 1971. Revogada pela Lei $n^{\circ} 9.394$, de 20 de dez de 1996. Disponível em $<$ http://www.planalto.gov.br/ccivil 03/leis/15692.htm>. Acesso em 27 nov. de 2014.

BRASIL. Lei n. 9.394, de 20 de dezembro de 1996. Estabelece as diretrizes e bases da educação nacional. Disponível em <http://www.planalto.gov.br/ccivil 03/leis//4024.htm>. Acesso em 18 set. 2014.

BRASIL. Lei n. 9.795, de 27 de abril de 1999. Institui a Política Nacional de Educação Ambiental. Disponível em $<$ http://www.planalto.gov.br/ccivil 03/leis/19795.htm>. Acesso em 09 de dez. de 2014.

BRASIL. Ministério do Meio Ambiente. Resolução CONAMA n. 275, de 25 de abril de 2001. Estabelece o código de cores para os diferentes tipos de resíduos. Disponível em http://www.mma.gov.br/port/conama/legiabre.cfm?codlegi=273. Acesso em 12 dez. 2014.

FREIRE, P. Pedagogia da Autonomia: Saberes necessários à prática educativa. São Paulo: Paz e Terra, 1996. 146 p.

GRAVATÁ, A.; PIZA, C.; MAYUMI, C.; SHIMAHARA, E. Volta ao mundo em 13 escolas: sinais do futuro no presente. São Paulo: Fundação Telefônica, 2013. 288p.

KRASILCHIK, M. Reforma e realidade: o caso do ensino das ciências. São Paulo em Perspectiva, São Paulo, v. 14 n. 1, p. 85 - 93, mar. 2000. Disponível em <http://www.scielo.br/pdf/spp/v14n1/9805.pdf>. Acesso em 01 dez. 2014. 
PERSICH, J.C.; SILVEIRA, D.D.S. Gerenciamento de Resíduos Sólidos - A importância da Educação Ambiental no Processo de implantação da Coleta Seletiva de lixo - o caso de ljiú - RS. Revista Eletrônica em Gestão, Educação e Tecnologia Ambiental REGET-CT/UFSM. n4, p. 416 - 426 , 2011. Disponível em <http://cascavel.ufsm.br/revistas/ojs2.2.2/index.php/reget/article/viewFile/3858/2264>. Acesso em 28 nov. 2014.

PACHECO, J.; EGGERTSDÓTTIR, R.; MARINÓSSON, G.L. Caminhos para a inclusão: um guia para o aprimoramento da equipe docente. Artmed: São Paulo, 2006.

PRÊMIO RESPOSTAS PARA O AMANHÃ. São Paulo: Samsung, 2014. Apresentam os vídeos das práticas pedagógicas vencedoras nacionais do Prêmio Respostas para o Amanhã. Disponível em $<$ https://www.samsung.com.br/respostasparaoamanha/>. Acesso em 12 Dez. 2014.

SOUZA, G.S.; POLIANA, B.M.; REIS, VR.; SANTOS, A.S.; DIAS, V.B. Educação Ambiental como ferramenta para o manejo de resíduos sólidos no cotidiano escolar. Revista Brasileira de Educação Ambiental, v. 8, n.2: 118130, 2013.

THIOLLENT, M. Metodologia da pesquisa ação. São Paulo: Cortez Editora, 1986.p. 14.

\section{ANEXO 1 \\ Questionário - Gestão de resíduos}

1 - Você separa o seu lixo?

( ) Não ( ) Sim ( ) Em parte

2 - Você considera importante separar o lixo?

( ) Não ( ) Sim ( ) Em parte

3 - Você incentiva outras pessoas a separarem o lixo?
( ) Não ( ) Sim ( ) Em parte

4 - Você sabe para onde vai o seu lixo?
( ) Não
( ) Sim ( ) Em parte

5 - Você sabe a diferença entre resíduo orgânico, reciclável e rejeito?
( ) Não
( ) Sim
( ) Em parte

6 - Você sabe onde deve descartar pilhas e baterias?

( ) Não ( ) Sim

7 - Você já ouviu falar na COOPACAM?

( ) Não ( ) Sim

8 - Algum grupo de catadores passa em seu bairro para coletar material reciclável?

( ) Não ( ) Sim ( ) Em parte

9 - Você acha que a sua escola deveria separar os resíduos?

( ) Não ( ) Sim ( ) Em parte 